\title{
Preparation of Thermoresponsive Grafted Polysilsesquioxane from Polyacrylamides Having Methoxysilyl End Group
}

\author{
By Osamu MoriYa, ${ }^{1, *}$ Syota YAMAmoto, ${ }^{1}$ Toyoshi MASUdA, ${ }^{1}$ Mikihiro KASHIo, ${ }^{2}$ and Toshio SUGIZAKI ${ }^{2}$
}

\begin{abstract}
(3-Mercaptopropyl)trimethoxysilane was employed as a chain transfer for the polymerization of $N$-isopropylacrylamide (NIPAM) and $N, N$-dimethylacrylamide (DMAA) under UV irradiation to obtain the corresponding polymers having methoxysilyl end group. By the condensation reaction of such macrosilane coupling reagents under basic or acidic conditions, the grafted polysilsesquioxanes, which were soluble in usual organic solvents, were formed without gelation. The cocondensation of the macrosilane coupling reagents enabled the preparation of the grafted polysilsesquioxane, in which poly(NIPAM) and poly(DMAA) were introduced respectively into the polysilsesquioxane main chain. Such macrosilane coupling reagents and the grafted polysilsesquioxanes showed an amphiphilic property. Furthermore, those containing poly(NIPAM) showed reversible thermoresponsive aggregation in an aqueous solution. In the thermoresponsive phase separation measured by turbidity, no change of aggregation temperature caused by the presence of poly(DMAA) was observed.

KEY WORDS: Polysilsesquioxane / Thermoresponsive Phase Separation / Poly $(N, N$-isopropylacrylamide) / Macrosilane Coupling

Reagent /
\end{abstract}

Silsesquioxane, which consisted of T-type siloxane bond, is a kind of useful inorganic-organic hybrid materials. From the interests in a new hybrid material, various investigations concerning the usages of oligo- and poly-silsesquioxane (PSQ) have been reported recently. ${ }^{1-5}$ In fact, the applications of such silsesquioxanes have been extended to electrical, optical, mechanical, and chemical fields. ${ }^{6-9}$ Most of those are performed by the modification of organic functional group, which is contained in the starting trialkoxy- or trichloro-silanes. The graft polymerization onto and from the silsesquioxane main chain has been also recognized as an effective method for the modification, in which the polymeric component provides an additional property besides durability for heat and weatherability based on the inorganic polysiloxane backbone. ${ }^{10-14}$ We also presented several reports concerning the grafted PSQ which intended to prepare a new multi-functional hybrid material. ${ }^{15-17}$ The synthesis of thermoresponsive PSQs, grafted the copolymer of $\mathrm{N}, \mathrm{N}$-dimethylacrylamide (DMAA) and $\mathrm{N}$ isopropylacrylamide (NIPAM), was an example utilizing the modification method. ${ }^{18-20}$ The PSQ, showing the stimuliresponsive property, has potential to be used in the practical material scenes of microencapsulation, biosensor, and drug delivery as postulated in the investigations concerning poly(NIPAM). ${ }^{21-27}$

For the grafting of the acrylamide polymers from PSQ back bone, the mercapto group was usable as a chain transfer specie in photo-polymerization. ${ }^{28-31}$ However, the condensation of sole (3-mercaptopropyl)trimethoxysilane (MTMS) to prepare the PSQ usually resulted in the formation of gel product insoluble in any solvent. Consequently, the co-condensation of MTMS with phenyltrimethoxysilane is required to obtain the
PSQ derivative, which was soluble in usual organic solvents. The corresponding functionalized gel is also useful and should be a convenient hybrid compound. Whereas, the PSQ soluble in a solvent is usable as a versatile material. Since, a homogeneous solution system is considered to perform the treatment and the reaction effectively in a molecular size mixture, when PSQ is utilized as a surfactant, an additive, and a component for the formation of interpenetrating material.

On the other hand, we reported the preparation of grafted PSQ by the use of living polymerization technique such as Reversible Addition-Fragmentation Chain Transfer process, in which the block copolymers of NIPAM and DMAA were introduced into PSQ main chain. ${ }^{20}$ Such previous results demonstrated that the sequence and the molecular weight of the polymer units in the graft chain showed no influence on the thermoresponsive aggregation temperature. The Lowest Critical Solution Temperatures (LCST) of the PSQs in an aqueous solution were recorded to be an almost same value irrespective of the presence of poly(DMAA) unit, which was relatively more hydrophilic and usually increase LCST of random copolymer with NIPAM. Therefore, the behavior is thought to be a characteristic of block copolymer of poly(NIPAM). ${ }^{32}$ The fact led us to examine the thermoresponsive behavior of another type of grafted PSQ, which had each poly(NIPAM) and poly(DMAA) on the same PSQ main chain. Such kind of grafted PSQ was assumed to be prepared readily by the use of the corresponding polymeric silane coupling reagents. If the polymeric coupling reagent prepared from MTMS is used as a building block, the resulting PSQ should be same to that obtained from sole MTMS. In other words, the synthetic route can avoid the gelation observed at the condensation using sole

\footnotetext{
${ }^{1}$ Department of Applied Chemistry, National Defense Academy, Hashirimizu, Yokosuka 239-8686, Japan

${ }^{2}$ Research Laboratory, Lintec Co., Nishiki-cho, Warabi 335-0005, Japan

*To whom correspondence should be addressed (Tel: +81-46-841-3810, Ext. 2404, Fax: +81-46-844-5901, E-mail: moriyaos@ @da.ac.jp).
} 


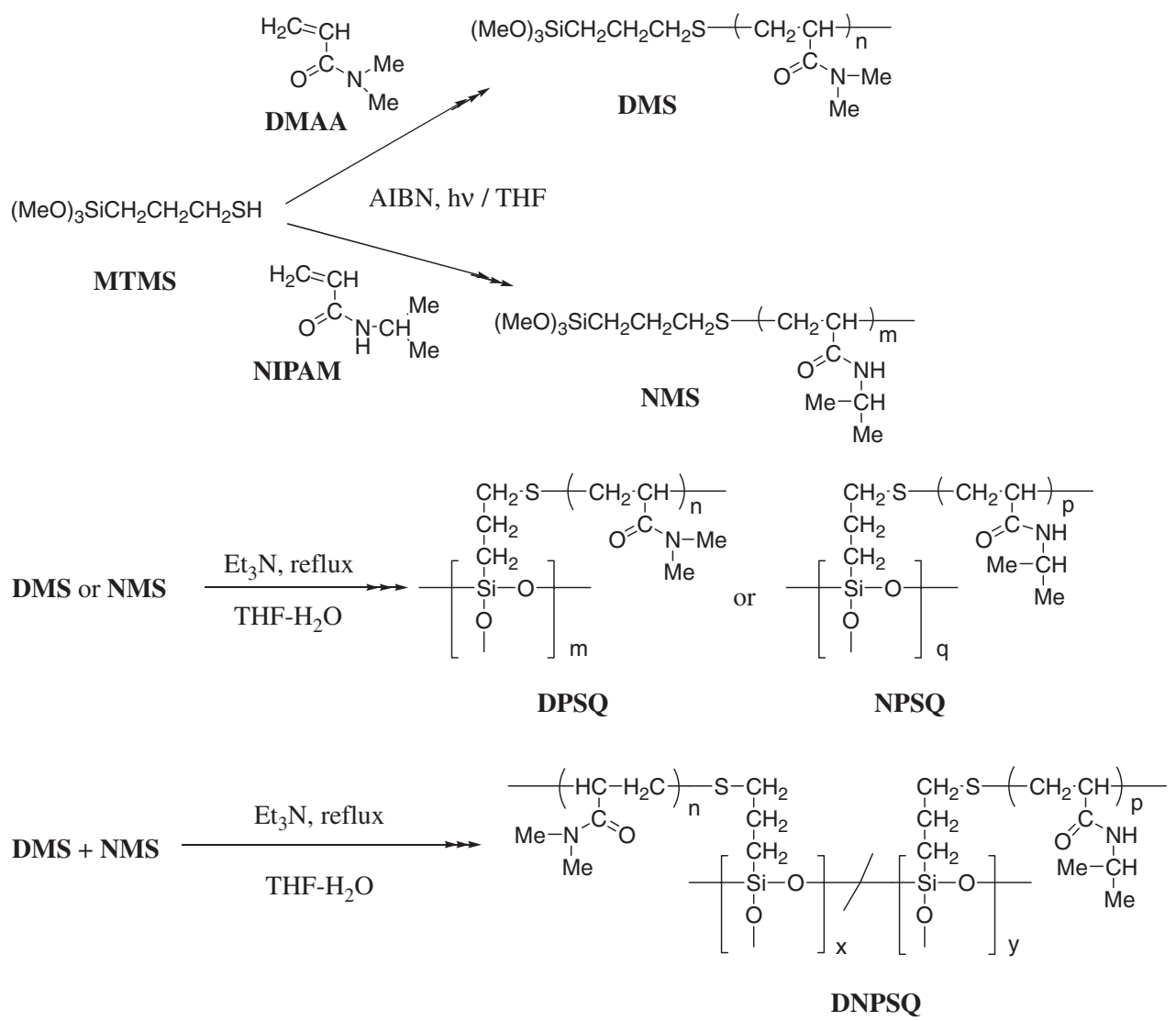

Scheme 1.

MTMS. In addition, the obtained PSQ derivative is a new kind of hybrid and expected to be usable in various scenes such as adsorption and adhesion materials. In these applications, both the hydrophilic and hydrophobic properties can be controlled by temperature and such characteristic may enable a fine separation and a changeable adhesive force in the use of column adsorbent and adhesive, respectively.

On the basis of the considerations mentioned above, the preparation and evaluation of the grafted PSQ as a new thermoresponsive hybrid are examined in this work. The trimethoxysilyl end-capped polymers have been already reported and utilized as the macrosilane coupling reagents. ${ }^{33,34}$ The radical polymerization by the use of MTMS is known as an effective procedure to prepare the coupling reagents. ${ }^{34}$ Therefore, the photo-polymerization technique was employed as a simple and a practical procedure for the preparation of poly(NIPAM) and poly(DMAA) from MTMS. In the formation of several kinds of grafted PSQ, the condensation reaction of the resulting macrosilane coupling reagents was examined under basic and acidic conditions. The syntheses of such materials were shown in Scheme 1.

\section{EXPERIMENTAL}

\section{General}

${ }^{1} \mathrm{H}$ NMR and ${ }^{13} \mathrm{C}$ NMR spectra were obtained on a JEOL
AL-300 and JNM A-500 spectrometer in $\mathrm{CDCl}_{3}$ or DMSO- $\mathrm{d}_{6}$. IR spectra were recorded on a JASCO FT/IR 230. Gel permeation chromatographic (GPC) analysis was carried out to estimate number-average molecular weight $\left(M_{\mathrm{n}}\right)$ and polydispersity $\left(M_{\mathrm{w}} / M_{\mathrm{n}}\right)$ on a Shimadzu LC-10VP chromatograph equipped with an evaporative light scattering detector. Three columns such as Shim-pack GPC-80MD, -804D, and -802D were connected in series and $N, N$-dimethylformamide (DMF) was used as the eluent. Calibration was performed using poly(methyl methacrylate) standards. Tetrahydrofuran (THF) employed for the reactions was distilled from sodium benzophenone ketyl before use. The monomer, NIPAM, was recrystallized from the mixed solvent of benzene and ${ }^{n}$ hexane. The other monomer, DMAA, was distilled over calcium hydride before use. $\alpha, \alpha^{\prime}$-azobisisobutyronitrile (AIBN) was recrystallized from methanol. Other reagents including MTMS (Chisso, 99\% purity) and 1,8-Diazabicyclo[5.4.0]-7-undecene (DBU) were used as supplied from commercial sources.

\section{Typical Procedure for Preparation of Polymer Having Methoxysilyl End Group as Macrosilane Coupling Reagent}

A solution of MTMS $(0.54 \mathrm{~g}, 2.70 \mathrm{mmol})$, DMAA $(4.00 \mathrm{~g}$, $40.35 \mathrm{mmol})$, and AIBN $(0.15 \mathrm{~g}, 0.91 \mathrm{mmol})$ in THF $(20 \mathrm{~mL})$ was introduced into a glass tube. The mixture was purged of air via three vacuum-argon cycles. Then, the mixture in the glass tube was irradiated at $18^{\circ} \mathrm{C}$ by using a RIKO RH400 UV lamp 
Table I. Preparation of macrosilane coupling reagent from MTMS

\begin{tabular}{|c|c|c|c|c|c|}
\hline \multirow[b]{2}{*}{ Run } & \multirow{2}{*}{$\begin{array}{c}\text { Reaction conditions }^{\mathrm{a}} \\
\text { Monomer } \\
\text { (Concentration [M]) }\end{array}$} & \multicolumn{4}{|c|}{ Macrosilane coupling reagent } \\
\hline & & $\begin{array}{c}\text { Product } \\
\left(\text { Yield }^{\mathrm{b}}, \%\right)\end{array}$ & $\begin{array}{l}\text { Silyl unit }{ }^{\mathrm{c}} \\
\text { mmol eq./g }\end{array}$ & $\begin{array}{l}\text { Monomer unit }^{\mathrm{c}} \\
\text { mmol eq./g } \\
\text { (Molar unit ratio } \\
\text { of monomer/Si) }\end{array}$ & $\begin{array}{c}M_{\mathrm{n}}{ }^{\mathrm{d}} \\
\left(M_{\mathrm{w}} / M_{\mathrm{n}}\right)\end{array}$ \\
\hline 1 & DMAA (2) & DMS (72) & 0.6 & $9.27(16.0)$ & $1900(2.36)$ \\
\hline 2 & NIPAM (2) & NMS (72) & 0.42 & $5.88(14.0)$ & $3600(2.92)$ \\
\hline 3 & NIPAM (5) & NMS (95) & 0.53 & $7.93(15.0)$ & $6100(4.45)$ \\
\hline
\end{tabular}

a The polymerization was conducted in $\mathrm{THF}$ at $18^{\circ} \mathrm{C}$ under UV irradiation by $400 \mathrm{~W}$ high pressure $\mathrm{Hg}$ lamp, in which 15 equiv. of the monomer to mercapto group were employed. The product was isolated as an insoluble part of diehtyl ether. ${ }^{b}$ Based on the contents of silyl unit, which were estimated from ${ }^{1} \mathrm{H}$ NMR spectral data. ${ }^{\mathrm{C}}$ Based on proton areas in ${ }^{1} \mathrm{H}$ NMR spectrum measured with

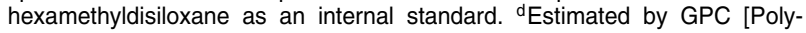
(methyl methacrylate) standard].

equipped with water jacket from a distance of $10 \mathrm{~cm}$ for $8 \mathrm{~h}$ under argon atmosphere. The resulting solution was distilled under reduced pressure to concentrate and the residue was poured into an excess amount of diethyl ether. The insoluble part was dried at room temperature for $24 \mathrm{~h}$ under reduced pressure $(<5 \mathrm{mmHg})$ to obtain the product (DMS), as a solid (3.24 g, 71\% yield based on weight, $72 \%$ yield based on silyl group, and $74 \%$ based on DMAA). The contents of mercaptopropyl group and DMAA unit in DMS were calculated from the corresponding peak areas observed in ${ }^{1} \mathrm{H}$ NMR spectrum, in which hexamethyldisiloxane was used as an internal standard (Table I, Run 1); IR (KBr) 2933, 1645 (C=O), 1501, 1356, 1258, 1140, $1083 \mathrm{~cm}^{-1} ;{ }^{1} \mathrm{H} \mathrm{NMR}\left(\mathrm{CDCl}_{3}, 500\right.$ $\mathrm{MHz}) \delta 0.66$ (br, - $\left.\mathrm{CH}_{2}-\mathrm{Si}-\right), 1.25-1.68$ (br m, $-\mathrm{CH}_{2}-$ ), 2.302.61 (br, (C=O)-C브-, $-\underline{\mathrm{CH}}_{2}-\mathrm{S}-$ ), 2.70-3.05 (br m, (C=O)-N$\mathrm{CH}_{3}$ ), 3.45 (br m, $\left.-\overline{\mathrm{OCH}}_{3}\right) ;{ }^{13} \mathrm{C} \mathrm{NMR}\left(125 \mathrm{MHz}, \mathrm{CDCl}_{3}\right) \delta 35.7$ $\left(-\underline{\mathrm{CH}_{2}}{ }_{2}\right), 35.8$ (- $\left.\underline{\mathrm{CH}}-\right), 37.1\left(-\mathrm{N}-\underline{\mathrm{CH}}_{3}\right), 50.6\left(-\mathrm{OCH}_{3}\right), 174.7$ $(-\underline{\mathrm{C}}=\mathrm{O}) ; \quad M_{\mathrm{n}}=1900, \quad M_{\mathrm{w}} / M_{\mathrm{n}}=2.36 ;$ silyl group $=0.60$ mmol equiv./g, methoxy group $=1.68$ mmol equiv. $/ \mathrm{g}$, DMAA unit $=9.27$ mmol equiv. $/ \mathrm{g}$.

Analogously, the polymerizations of NIPAM were carried out under the different monomer concentrations such as 2 [M] and $5[\mathrm{M}]$ in THF solution. The spectral data of the obtained polymer (NMS) in the polymerization of the former monomer concentration was as follows; IR (KBr) 3400 (-NH-), 2970, $1648(\mathrm{C}=\mathrm{O}), 1546,1460,1368,1174,1067 \mathrm{~cm}^{-1} ;{ }^{1} \mathrm{H} \mathrm{NMR}$ $\left(\mathrm{CDCl}_{3}, 500 \mathrm{MHz}\right) \delta 0.73$ (br, $\left.-\mathrm{CH}_{2}-\mathrm{Si}-\right), 1.09$ (br, $\left.-\underline{\mathrm{CH}}_{3}\right), 1.45-$ 1.80 (br m, - $\underline{\mathrm{H}}_{2}-$ ), 2.00-2.61 (br, (C=O)-C $\underline{\mathrm{H}}-,-\mathrm{C}_{2}-\mathrm{S}-$ ), 3.50 (br, $\left.-\mathrm{OCH}_{3}\right), 3.95$ (br, -NH-CH-); ${ }^{13} \mathrm{C} \mathrm{NMR}(125 \mathrm{MHz}$, $\left.\mathrm{CDCl}_{3}\right) \delta 22.6\left(-\underline{\mathrm{CH}}_{3}\right), 34.2$ (- $\left.\underline{\mathrm{CH}}_{2}-\right), 34.8$ (-ㅁH-), 41.4 (-N-CH-), $50.6\left(-\mathrm{OCH}_{3}\right), 174.7(-\mathrm{C}=\mathrm{O}) ; M_{\mathrm{n}}=3600, M_{\mathrm{w}} / M_{\mathrm{n}}=2.76$; silyl group $=0.42$ mmol equiv. $/ \mathrm{g}$, methoxy group $=1.13$ mmol equiv. $/ \mathrm{g}$, NIPAM unit $=5.88 \mathrm{mmol}$ equiv. $/ \mathrm{g}$.

The results of syntheses of the macrosilane coupling reagents were listed in Table I.

\section{Typical Procedure for Condensation of Macrosilane Cou- pling Reagent}

DMS ( $0.13 \mathrm{~g}$, silyl group: $0.08 \mathrm{mmol}$ equiv.), NMS ( $0.38 \mathrm{~g}$, Si group: $0.16 \mathrm{mmol}$ eqiv.), $M_{\mathrm{n}}$ of which was 4000 (Table I, Run 2), and triethylamine $\left(\mathrm{Et}_{3} \mathrm{~N}, 0.002 \mathrm{~g}, 0.02 \mathrm{mmol}\right)$ in $\mathrm{THF}$
$(2 \mathrm{~mL})$ and water $(0.5 \mathrm{~mL})$ was refluxed for $24 \mathrm{~h}$. The resulting solution was concentrated by a rotary evaporator under reduced pressure and, then, an excess amount of diethyl ether was added to the residual oil. The precipitated solid was collected and dried at room temperature for $24 \mathrm{~h}$ in a vacuum oven under reduced pressure $(<5 \mathrm{mmHg})$ to obtain DNPSQ1 $(0.43 \mathrm{~g}, 83 \%$ yield based on silyl group). The contents of the monomer units and silyl group were calculated from the corresponding peak areas observed in ${ }^{1} \mathrm{H}$ NMR spectrum, in which hexamethyldisiloxane was used as an internal standard (Table III, Run 4); IR (KBr) 3440 (-NH-), 2973, 1643 (C=O), 1546, 1460, 1387, 1258, 1130, 1097 (Si-O), $628 \mathrm{~cm}^{-1}$; ${ }^{1} \mathrm{H}$ NMR $(300 \mathrm{MHz}$, $\left.\mathrm{CDCl}_{3}\right) \delta 0.63$ (br, -Si-C $\underline{\mathrm{H}}_{2}-$ ), 1.09 (br, $-\mathrm{CH}_{3}$ ), 1.50-1.85 (br,

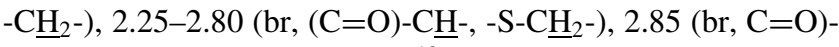
$\left.\mathrm{N}-\mathrm{CH}_{3}\right), 3.95$ (br, -NH-CH-); ${ }^{13} \mathrm{C} \mathrm{NMR}\left(75.45 \mathrm{MHz}, \mathrm{CDCl}_{3}\right)$ $\delta 22.6\left(-\underline{C H}_{3}\right), 35.3\left(-\underline{C H}_{2}-\right), 35.8$ (-ㄷH-), $37.2\left(-\mathrm{N}-\underline{C H}_{3}\right), 41.3$ $(-\mathrm{N}-\underline{\mathrm{CH}}-), \quad 174.5 \quad(-\underline{\mathrm{C}}=\mathrm{O}) ; \quad M_{\mathrm{n}}=13600, \quad M_{\mathrm{w}} / \bar{M}_{\mathrm{n}}=1.32 ;$ silyl group $=0.20 \mathrm{mmol}$ equiv. $/ \mathrm{g}$, DMAA unit $=7.65 \mathrm{mmol}$ equiv./g, NIPAM unit $=3.21 \mathrm{mmol}$ equiv. $/ \mathrm{g}$.

Analogously, the condensation and co-condensation of the macrosilane coupling reagents were carried out under various conditions. The results were listed in Table II and Table III.

\section{Measurement of Transmittance (\% $\mathrm{T})$}

$1.0 \mathrm{wt} \%$ solution of the product containing poly(NIPAM) in deionized water was used for the measurement of transmittance (\%T) on a Shimadzu UV-1650 spectrophotometer equipped with a Peltier-type S-1700 thermostatic cell holder. In the measurements, the changes of $\% \mathrm{~T}$ were observed from a visible source at $600 \mathrm{~nm}$ through a $1 \mathrm{~cm}$ quartz sample cell at the rate of $1{ }^{\circ} \mathrm{C} / 30 \mathrm{~s}$ during heating and cooling scans. The measurements were repeated at least three times on each sample until when the observed curves were in good agreement.

\section{RESULTS AND DISCUSSION}

Preparation of Macrosilane Coupling Reagent from MTMS

When we tried to prepare the PSQ having mercapto groups by condensation reaction using only MTMS under basic conditions, the product insoluble in usual organic solvents was obtained. By considering the previous works concerning the syntheses of PSQs, the use of trimethoxysilane having a substituent, which is bulky or shows a mutual interaction such as $\pi-\pi$ stacking, seems to be free from the gelation. ${ }^{1-5}$ Therefore, the silane coupling reagent, which possess a bulky polymeric component, is supposed to be a candidate for preparing PSQ derivative without gelation.

The polymerization of DMAA or NIPAM with MTMS in THF solution was conducted under UV irradiation in the presence of a catalytic amount of AIBN. In the polymerizations, 15 equiv. of the monomer to MTMS were used. The results were shown in Table I. From the polymerization conducted in $2[\mathrm{M}]$ solution of DMAA, the product, DMS, was obtained in $72 \%$ yield and showed the slightly larger $M_{\mathrm{n}}$ such as 1900 compared to the calculated value of 1700 (Table I, Run 1). Analogously, the polymerizations of NIPAM 
were carried out, in which the monomer concentrations were adjusted to be 2 [M] and 5 [M] (Table I, Run 2 and Run 3). In these cases, the corresponding polymers, NMSs were obtained in over $72 \%$ yield. However, the $M_{\mathrm{n}}$ s showed the larger values such as 3600 and 6100 in comparison with the calculated $M_{\mathrm{n}}$ such as 1900. In the analyses of ${ }^{1} \mathrm{H}$ NMR spectra of DMS and NMSs, the decrease of the proton ratio assigned to methoxy group, which should indicate the progress of condensation, was not so obvious. Consequently, the results suggest that the association of the polymeric molecules occurs. Another possible reason to explain the unexpected values of $M_{\mathrm{n}}$ is the coupling reaction during the polymerization. The radical coupling results in the introduction of two methoxysilyl end groups at the both ends of polymer and should lead to the gel product in the condensation of methoxysilyl groups. However, no obvious gelation was observed in the successive condensation reaction using NMS (Table I, Run 2) under the conditions mentioned here. Consequently, the former speculation seems to explain the unexpected lager $M_{\mathrm{n}} \mathrm{s}$ of NMSs.

The formation of the polymers having methoxysilyl end group was confirmed by the IR and NMR spectra. In the IR spectra of DMS and NMSs, the strong absorbance at $c a$. $1640 \mathrm{~cm}^{-1}$ due to carbonyl group was observed. The absorption around $1100 \mathrm{~cm}^{-1}$ was assigned to silicon-oxygen bond of methoxysilyl group. In the ${ }^{1} \mathrm{H}$ NMR spectra of DMS and NMSs, the small signal due to methylene protons bonded to $\mathrm{Si}$ was recognized at $c a$. $0.6 \mathrm{ppm}$. The signals assigned to methyl protons of methoxy group were appeared at $3.4 \mathrm{ppm}$. The contents of silyl group and methoxy group in the polymers were based on the peak areas of these signals. The signal due to methyl protons of dimethylamino group of DMAA unit was observed around $3.0 \mathrm{ppm}$. The signal appeared at $3.86 \mathrm{ppm}$ was assigned to the methine proton bonded to nitrogen of NIPAM unit. The respective peak areas of the signals at 3.0 and $3.86 \mathrm{ppm}$ were utilized for the calculation of content of the monomer units. The ${ }^{1} \mathrm{H}$ NMR spectrum of DMS (Table I, Run 1) was shown in Figure 1 and that of NMS (Table I, Run 2) was in Figure 2, respectively. ${ }^{13} \mathrm{C}$ NMR spectra of DMS and NMSs also supported the formation of the desired polymers. The signals observed in the range of $37 \mathrm{ppm}$ to $42 \mathrm{ppm}$ were assigned to the carbons of methyl and methine groups bonded to nitrogen of DMAA and NIPAM units. The signal detected at $175 \mathrm{ppm}$ was assigned to the carbon of carbonyl group. The signals assigned to methylene carbons of MTMS group were difficult to detect, but that observed at $50 \mathrm{ppm}$ indicated the presence of methoxy group. The spectral information demonstrated that the polymerization proceeded effectively to give the polymers having methoxysilyl end group. The obtained polymers, DMS and NMSs, were soluble in water, methanol, THF, chloroform, and DMF, but insoluble in diethyl ether and ${ }^{n}$ hexane.

\section{Condensation of Macrosilane Coupling Reagent}

The condensation of DMS to give the corresponding PSQ derivative was carried out under various conditions. The results were listed in Table II. In the condensations, the mole ratio of

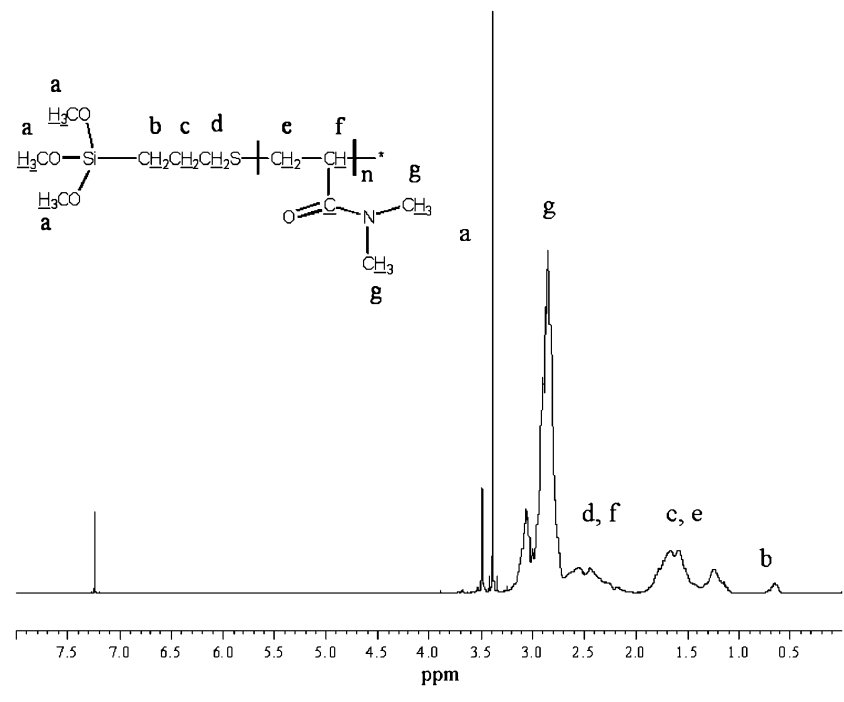

Figure 1. ${ }^{1} \mathrm{H}$ NMR spectrum of DMS.

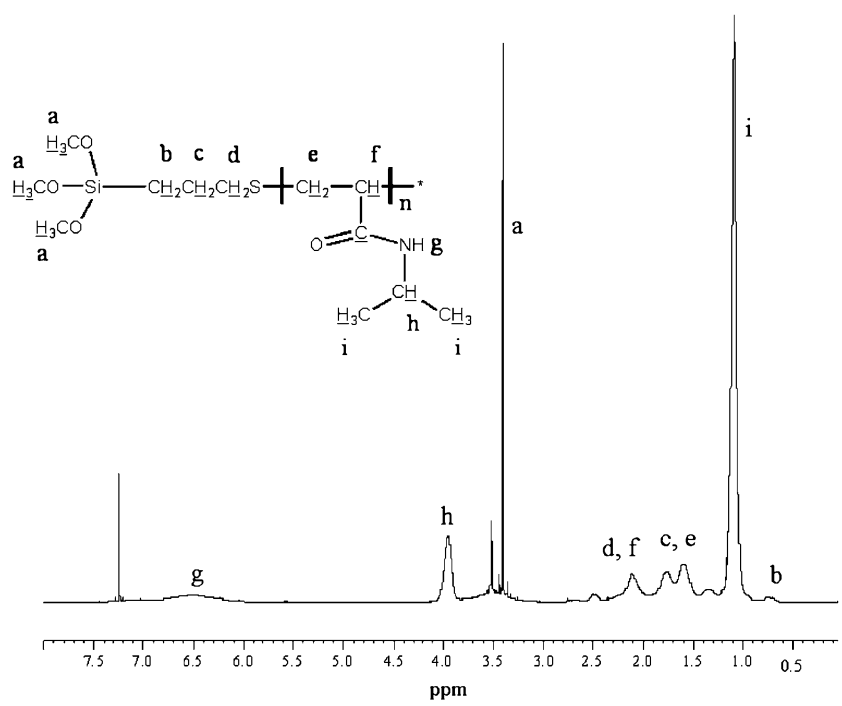

Figure 2. ${ }^{1} \mathrm{H}$ NMR spectrum of NMS (Table I, Run 2).

base or acid to silyl group was adjusted to be $5 \mathrm{~mol} \%$. When the condensation of DMS in the mixed solvents of THF and water with a catalytic amount of triethylamine was carried out under reflux for $24 \mathrm{~h}$, the corresponding PSQ (DPSQ) was isolated from diethyl ether as an insoluble solid in $67 \%$ yield (Table II, Run 1). The $M_{\mathrm{n}}$ of DPSQ estimated by GPC was 17700. In the condensation conducted for $72 \mathrm{~h}$, the yield and $M_{\mathrm{n}}$ were increased to be $81 \%$ and 29200 , respectively (Table II, Run 5). However, in the reactions continued for more than $72 \mathrm{~h}$, no obvious increase of yield and $M_{\mathrm{n}}$ was observed. Sodium hydroxide and DBU were also effective basic catalysts for the condensation (Table II, Run 2 and 3). The condensation analogously proceeded under acidic conditions where a catalytic amount of methanesulfonic acid was used. In this case, the yield was $94 \%$ and $M_{\mathrm{n}}$ was estimated to be 13400 (Table II, Run 4). In those condensations, the yields 
Table II. Preparation of DPSQ by condensation of DMS

\begin{tabular}{|c|c|c|c|c|c|}
\hline \multirow[b]{2}{*}{ Run } & \multicolumn{3}{|c|}{ Reaction conditions $^{a}$} & \multicolumn{2}{|c|}{ DPSQ } \\
\hline & $\begin{array}{c}\text { Organic } \\
\text { solvent }\end{array}$ & Catalyst & $\begin{array}{c}\text { Time } \\
h\end{array}$ & $\begin{array}{c}\text { Yield }^{\mathrm{b}} \\
\%\end{array}$ & $M_{\mathrm{n}}^{\mathrm{c}}\left(M_{\mathrm{w}} / M_{\mathrm{n}}\right)$ \\
\hline 1 & THF & $\mathrm{Et}_{3} \mathrm{~N}$ & 24 & 67 & $17700(1.32)$ \\
\hline 2 & THF & $\mathrm{NaOH}$ & 24 & 67 & 16900 (1.39) \\
\hline 3 & THF & DBU & 24 & 84 & $17100(1.44)$ \\
\hline 4 & THF & $\mathrm{CH}_{3} \mathrm{SO}_{3} \mathrm{H}$ & 24 & 94 & $13400(2.17)$ \\
\hline 5 & THF & $\mathrm{Et}_{3} \mathrm{~N}$ & 72 & 81 & $29200(1.43)$ \\
\hline
\end{tabular}

a The reaction was conducted under reflux conditions in organic solvent with $\mathrm{H}_{2} \mathrm{O}$, in which the volume ratio of organic solvent/ $\mathrm{H}_{2} \mathrm{O}$ was adjusted to be $4 / 1$. The product was isolated as an insoluble part of diethyl ether. ${ }^{b}$ Based on the content of silyl unit, which was calculated by the proton areas in ${ }^{1} \mathrm{H}$ NMR spectrum measured with hexamethyldisiloxane as an internal standard. ' Estimated by GPC [Poly(methyl methacrylate) standard].

Table III. Preparation of NPSQ and DNPSQ by condensation of NMS and DMS

\begin{tabular}{|c|c|c|c|c|c|c|}
\hline & \multicolumn{3}{|c|}{ Reaction conditions ${ }^{a}$} & \multicolumn{3}{|c|}{ Grafted PSQ } \\
\hline Run & Polymer & $\begin{array}{c}\text { Monomer unit } \\
\text { ratio of } \\
\text { DMAA/NIPAM }\end{array}$ & $\begin{array}{c}\text { Reaction } \\
\text { Time } \\
\mathrm{h}\end{array}$ & $\begin{array}{l}\text { Product } \\
\text { (Yield, }{ }^{b} \\
\% \text { ) }\end{array}$ & $\begin{array}{l}\text { Monomer unit } \\
\text { ratio of } \\
\text { DMAA/NIPAM }\end{array}$ & $\begin{array}{c}M_{\mathrm{n}}{ }^{\mathrm{c}} \\
\left(M_{\mathrm{w}} / M_{\mathrm{n}}\right)\end{array}$ \\
\hline 1 & NMS & - & 3 & $\begin{array}{c}\text { NPSQ1 } \\
(79)\end{array}$ & - & $\begin{array}{c}6100 \\
(2.46)\end{array}$ \\
\hline 2 & NMS & - & 24 & $\begin{array}{c}\text { NPSQ2 } \\
(86)\end{array}$ & - & $\begin{array}{l}11300 \\
(1.95)\end{array}$ \\
\hline 3 & NMS & - & 120 & $\begin{array}{c}\text { NPSQ3 } \\
(94)\end{array}$ & - & $\begin{array}{l}23100 \\
(1.35)\end{array}$ \\
\hline 4 & $\begin{array}{l}\text { DMS, } \\
\text { NMS }\end{array}$ & 0.5 & 24 & $\begin{array}{c}\text { DNPSQ1 } \\
(83)\end{array}$ & 0.4 & $\begin{array}{l}13600 \\
(1.82)\end{array}$ \\
\hline 5 & $\begin{array}{l}\text { DMS, } \\
\text { NMS }\end{array}$ & 2.0 & 24 & $\begin{array}{c}\text { DNPSQ2 } \\
(75)\end{array}$ & 1.7 & $\begin{array}{l}13200 \\
(1.89)\end{array}$ \\
\hline
\end{tabular}

a The reaction was conducted with $5 \mathrm{~mol} \%$ of triethylamine to silyl group in the mixed solvents of THF and water under reflux, in which NMS, showing $M_{n}$ of 3600 (Table I, Run 2), was used and the product was isolated as an insoluble part of diethyl ether. ${ }^{\text {b }}$ Based on the content of silyl group, which was calculated from proton ratios in ${ }^{1} \mathrm{H}$ NMR spectrum measured with hexamethyldisiloxane as an internal standard. ${ }^{\mathrm{C}}$ Estimated by GPC [Poly(methyl methacrylate) standard]

of DPSQ were based on the content of silyl group, which was calculated from the proton area of the signal detected at $0.6 \mathrm{ppm}$ in ${ }^{1} \mathrm{H}$ NMR spectra.

The procedure using $\mathrm{Et}_{3} \mathrm{~N}$ catalyst was applied to the condensation of NMS, $M_{\mathrm{n}}$ of which was 3600 (Table I, Run 2), and co-condensation with DMS as shown in Table III. The condensation of NMS also proceeded effectively and afforded the PSQ derivative (NPSQ). Three kinds of NPSQ, $M_{\mathrm{n}} \mathrm{s}$ of which were 6100 (NPSQ1), 11300 (NPSQ2), and 23100 (NPSQ3), were prepared by changing the reaction time, respectively (Table III, Run 1-3). Analogously, the co-condensations of NMS with DMS, in which the monomer unit ratios of DMAA/NIPAM were adjusted to be 0.5 and 2, were tried. These co-condensations afforded the corresponding PSQs in over $75 \%$ yield (Table III, Run 4 and 5). The monomer unit ratio of DMAA/NIPAM in the grafted PSQ (DNPSQ1), obtained from the former feed ratio, was estimated to be 0.4 . In the case of the later feed mole ratio, the resulting PSQ (DNPSQ2) showed 1.7 of the monomer unit ratio of DMAA/NIPAM. As an example, ${ }^{1} \mathrm{H}$ NMR spectrum of DNPSQ1 was shown in Figure 3. The respective $M_{\mathrm{n}} \mathrm{s}$ of

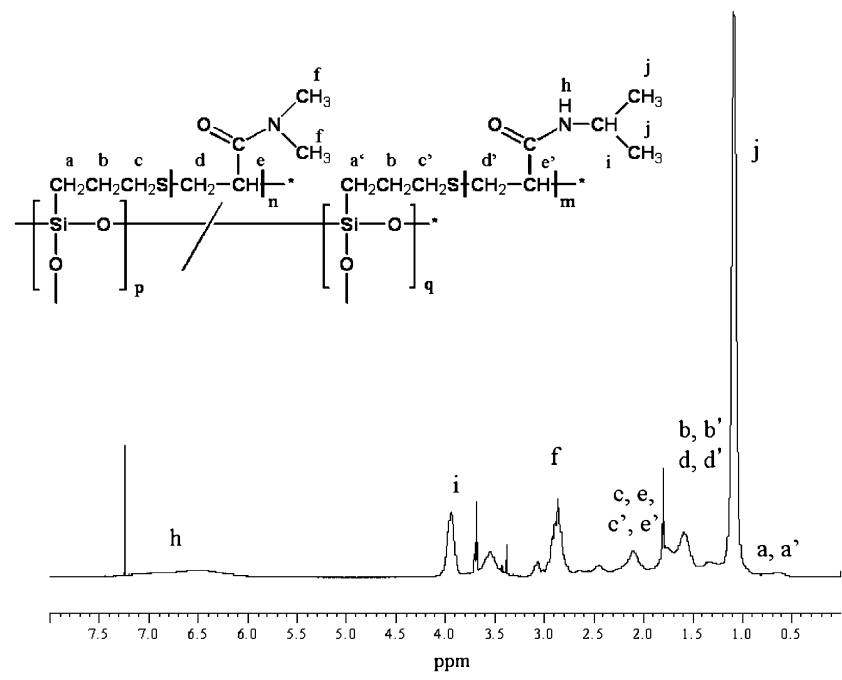

Figure 3. ${ }^{1} \mathrm{H}$ NMR spectrum of DNPSQ1.

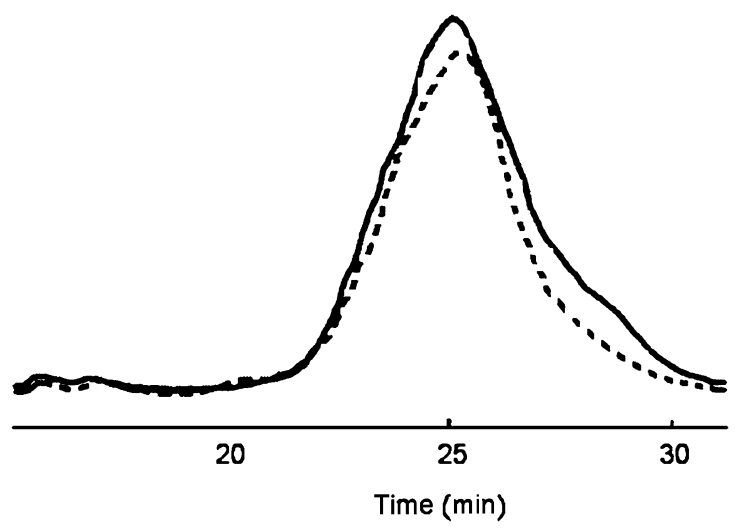

Figure 4. GPC chromatograms of NPSQ2 (---) and DNPSQ1 (-).

DNPSQ1 and DNPSQ2 were 13600 and 13200. In such GPC chromatograms, the product was detected as a unimodal peak. The observation of unimodal peak suggested that the condensations of DMS and NMS proceeded at the same time and showed an analogous reactivity. This was thought to be the supporting data for the co-condensation. For the examples, the chromatograms of NPSQ2 and DNPSQ1 were shown in Figure 4. Thus, the PSQ derivatives, which had the graft chains of poly(NIPAM) and poly(DMAA), were obtained efficiently through the building up procedure by the use of the macrosilane coupling reagents. The obtained PSQs, containing poly(NIPAM) in the graft chains, were employed for the evaluation of thermoresponsive behavior.

\section{Thermally Reversible Phase Separation}

The thermoresponsive aggregation was indicated by the turbidity measured as $\% \mathrm{~T}$ at $600 \mathrm{~nm}$ under heating and cooling. All the samples mentioned here showed the reversible thermoresponsive phase separation in an aqueous solution. However, except for the case of NMS, the plots under cooling were not depicted in the following Figures for easy viewing. 


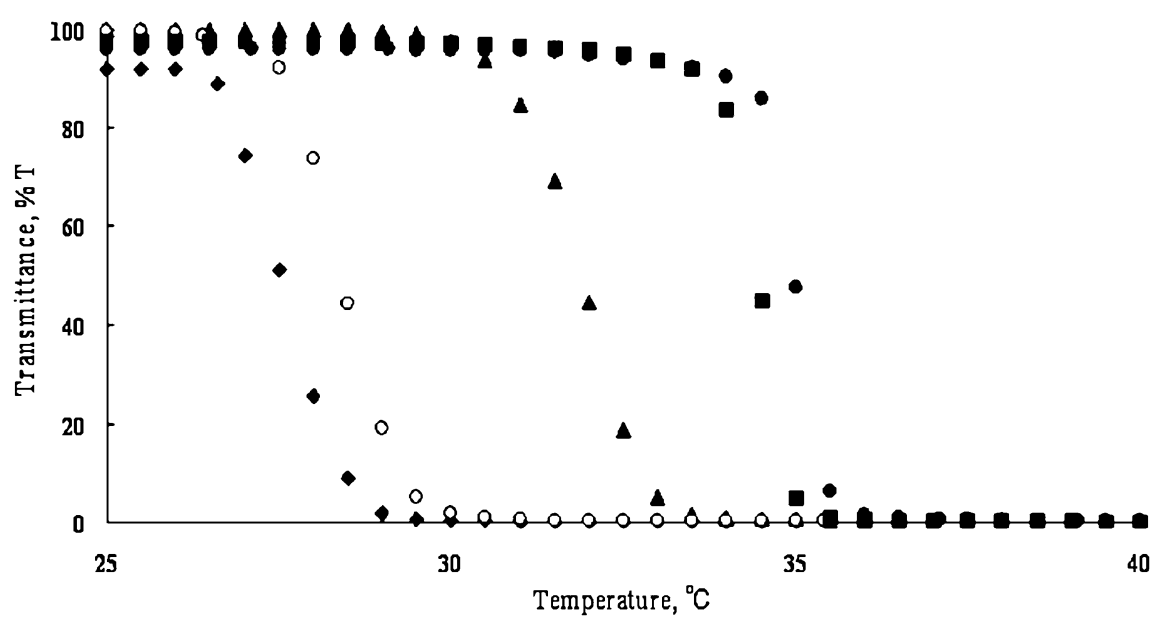

Figure 5. Temperature dependence of optical transmittance (\%T) at $600 \mathrm{~nm}$ for $1 \mathrm{wt} \%$ aqueous solution of NMS (Table I, Run 2, 0 : Heating, $\bigcirc$ : Cooling), NPSQ1 ( $\square$ : Heating), NPSQ2 ( $\Delta$ : Heating), and NPSQ3 $(\bullet:$ Heating).

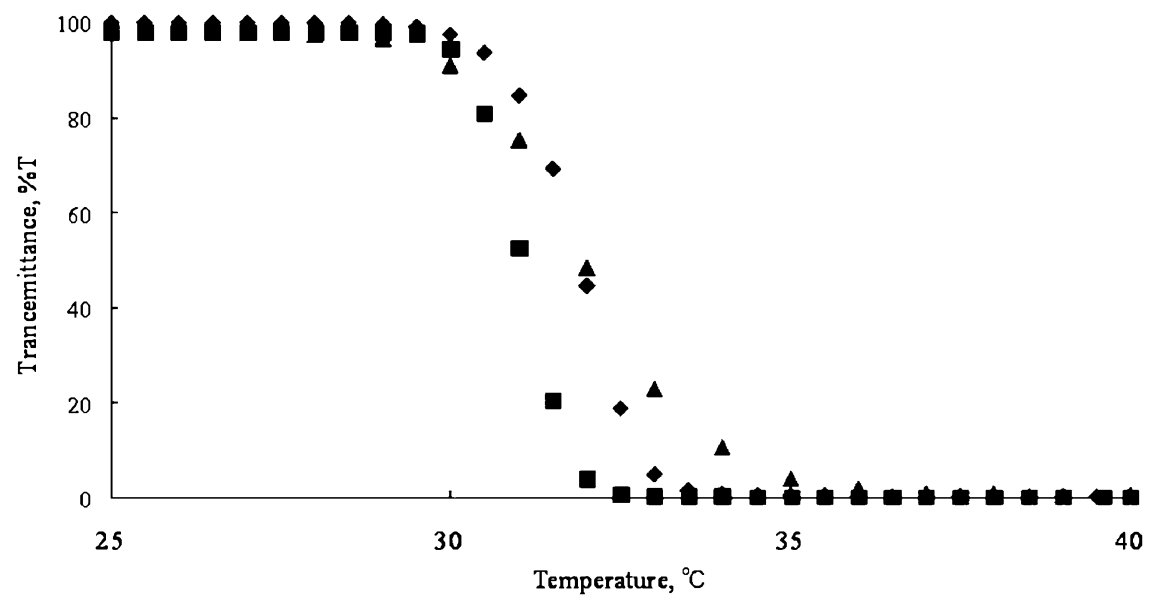

Figure 6. Temperature dependence of optical transmittance (\%T) at $600 \mathrm{~nm}$ for $1 \mathrm{wt} \%$ aqueous solution of NPSQ2 (ロ: Heating), DNPSQ1 ( DNPSQ2 ( $\mathbf{A}$ : Heating).

In the aqueous solution of $1 \mathrm{wt} \%$ of NMS, $M_{\mathrm{n}}$ of which was 3600 (Table I, Run 2), the phase separation started at $34^{\circ} \mathrm{C}$ and reached to $0 \% \mathrm{~T}$ at $\mathrm{ca} .36^{\circ} \mathrm{C}$ under heating as shown in Figure 5. Under cooling, the transmittance began to increase at $30^{\circ} \mathrm{C}$ and a transparent solution was recovered at $28^{\circ} \mathrm{C}$. The aggregation of NPSQ1, NPSQ2, and NPSQ3 began at $33^{\circ} \mathrm{C}$, $31^{\circ} \mathrm{C}$, and $28^{\circ} \mathrm{C}$, respectively. The results demonstrated that the increase of $M_{\mathrm{n}}$ led to the decrease of LCST. This may be explained by the speculation that the aggregation of a smaller number of polymeric molecules was enough to bring about the obvious decrease of \% $\mathrm{T}$ in the case of NPSQ3 showing a larger $M_{\mathrm{n}}$. In other words, the removal of a smaller number of water molecules around NIPAM units, which can be achieved by a smaller energy, seems to lead to the effective hydrophobic aggregation.

Next, the thermoresponsive behavior of the PSQs having two kinds of graft chains, one of which was poly(DMAA), was examined. The random copolymer of NIPAM and DMAA generally shows a higher LCST than the homopolymer of NIPAM. ${ }^{35-37}$ The introduction of poly(DMAA), which was recognized as a more hydrophilic component than poly(NIPAM), provided a hydrophilic environment. However, the recorded values of LCST of DNPSQ1 and DNPSQ2 were same to that observed in the case of NPSQ2 as shown in Figure 6. Such phase separation behavior of DNPSQs was similar to that of the block copolymer of NIPAM, in which no influence of presence of poly(DMAA) unit was observed..$^{32}$ The presence of poly(DMAA) was indicated by the change of sensitivity of aggregation to temperature. In the aqueous solution of NPSQ2, the aggregation started at $30^{\circ} \mathrm{C}$ and was completed at $32^{\circ} \mathrm{C}$. While, the temperature range from $30^{\circ} \mathrm{C}$ to $36^{\circ} \mathrm{C}$ was recorded in the case of DNPSQ2. The results of thermoresponsive behavior of the PSQs demonstrated that the graft chains of poly(NIPAM) began to aggregate irrespective of a hydrophilic environment provided by poly(DMAA). This may be explained by the situation of poly(NIPAM), which is introduced as a block. In the random copolymer, the presence of the hydrophilic monomer unit near NIPAM unit was unfavorable to remove water molecules efficiently around them. Contrary to this, when NIPAM units are located as a 
block, the interpenetration of hydrophilic units is difficult. This should enable to keep a hydrophobic environment around poly(NIPAM) chain. In the analogous reason, the block copolymer of NIPAM and DMAA showed the similar behavior irrespective of the composition of the both polymeric components as shown in the previous works including us. ${ }^{20,32}$ Thus, when the graft chains of poly(NIPAM) and poly(DMAA) were introduced respectively, the thermoresponsive behavior of the grafted polymer essentially controlled by the sole poly(NIPAM) chains. In addition, it may be allowed to say that the presence of the relatively hydrophilic poly(DMAA) chains in DNPSQs only retards the nimble aggregation between the grafted PSQ molecules.

\section{CONCLUSION}

The use of MTMS for the polymerization of NIPAM and DMAA under UV irradiation enabled the preparation of the corresponding polymers having methoxysilyl end group. The polymers were utilized as the macrosilane coupling reagents and the building blocks for the PSQ derivatives. Furthermore, the condensation of the macrosilane coupling reagents was effective for the formation of the grafted PSQ containing the different kinds of graft chains in the same main chain. Through those steps, no obvious gelation was observed. Consequently, the procedure presented a usable synthetic route for the multifunctional organic-inorganic hybrid polymers based on PSQ structure, which were soluble in usual organic solvents.

In the thermoresponsive behavior of the grafted PSQ containing poly(NIPAM), the effect of $M_{\mathrm{n}}$ on LCST was observed. Contrary to this, no hydrophilic influence due to the presence of poly(DMAA) graft chains on LCST was observed. Even in the case of DNPSQ2, which contained the larger number of poly(DMAA) chain, LCST was same to that of NPSQ2 having only poly(NIPAM) graft chains. These suggests that the additional functional groups can be introduced without change of thermoresponsive behavior, when poly(NIPAM) component is existed as a block. The information seems to be helpful for designing a multi-functional PSQ.

Received: March 19, 2008

Accepted: July 19, 2008

Published: September 4, 2008

\section{REFERENCES}

1. R. H. Baney and X. Cao, "Silicon-Containing Polymers," R. G. Johns, W. Ando, J. Chojnowski, Ed., Kluwer, Dordrecht, 2000.

2. M. M. Sprung and F. O. Guenther, J. Polym. Sci., 28, 17 (1958).

3. J. F. Brown, Jr, L. H. Vogt, Jr, A. Katchman, J. W. Eustance, K. M.
Kaiser, and K. W. Krantz, J. Am. Chem. Soc., 82, 6194 (1960).

4. R. H. Baney, M. Itoh, A. Sakakibara, and T. Suzuki, Chem. Rev., 95, 1409 (1995).

5. T. Kondo, K. Yoshi, K. Horie, and M. Itoh, Macromolecules, 33, 3650 (2000).

6. A. Gozdz, Polym Adv. Technol., 5, 70 (1994).

7. T. Tanaka, M. Morita, and K. Onose, Jpn. J. Appl. Phys., 24, L112 (1985).

8. C.-L. Chiang and C.-C. M. Ma, J. Polym. Sci., Polym. Chem. Ed., 41, 1371 (2003).

9. G. Krishnan and C. He, Macromol. Chem. Phys., 204, 531 (2003).

10. J. Pyun and K. Matyjaszewski, Chem. Mater., 13, 3436 (2001).

11. K.-M. Kim, D.-K. Keum, and Y. Chujo, Macromolecules, 36, 867 (2003).

12. G. Cardoen and E. B. Coughlin, Macromolecules, 37, 5123 (2004).

13. B. X. Fu, A. Lee, and T. S. Haddad, Macromolecules, 37, 5211 (2004).

14. K. Ohno, S. Sugiyama, K. Koh, Y. Tsujii, T. Fukuda, M. Yamahiro, H. Oikawa, Y. Yamamoto, N. Ootake, and K. Watanabe, Macromolecules, 37, 8517 (2004).

15. O. Moriya, S. Yamamoto, S. Kumon, T. Kageyama, A. Kimura, and T. Sugizaki, Chem. Lett., 33, 224 (2004).

16. T. Sugizaki, M. Kashio, A. Kimura, S. Yamamoto, and O. Moriya, J. Polym. Sci., Polym. Chem. Ed., 42, 4212 (2004).

17. S. Yamamoto, T. Shimada, A. Kimura, T. Sugizaki, and O. Moriya, Polym. J., 36, 761 (2004).

18. O. Moriya, M. Kuga, S. Yamamoto, M. Kashio, A. Kamejima, and T. Sugizaki, Polymer, 47, 1837 (2006).

19. S. Yamamoto, F. Minami, T. Masuda, O. Moriya, M. Kashio, and T. Sugizaki, Polymer, 47, 7693 (2006).

20. T. Masuda, S. Yamamoto, O. Moriya, M. Kashio, and T. Sugizaki, Polym. J., 39, 220 (2007).

21. J. E. Guillet, J. Macromol. Sci., Chem., A2, 1441 (1968).

22. S. Fujishige, K. Kubota, and I. Ando, J. Phys. Chem., 93, 3311 (1989).

23. G. H. Chen and A. S. Hoffman, Nature, 373, 49 (1995)

24. R. H. Pelton, Adv. Colloid. Interface Sci., 85, 1 (2000).

25. B. Ray, Y. Isobe, K. Matsumoto, S. Habaue, Y. Okamoto, M. Kamigaito, and M. Sawamoto, Macromolecules, 37, 1702 (2004).

26. S. Meyer and W. Richtering, Macromolecules, 38, 1517 (2005).

27. K. S. Kim and B. Vincent, Polym. J., 37, 565 (2005).

28. K. M. Huh, J. Hashi, T. Ooya, and N. Yui, Macromol. Chem. Phys., 201, 613 (2000).

29. P. Xia and D. Yan, J. Appl. Polym. Sci., 45, 579 (1992).

30. G. Chen, Y. Imanishi, and Y. Ito, Macromolecules, 31, 4379 (1998).

31. L. Lecamp, F. Houllier, B. Youssef, and C. Bunel, Polymer, 42, 2727 (2001).

32. C. Yang and Y. L. Cheng, J. Appl. Polym. Sci., 102, 1191 (2006).

33. H. R. Kricheldorf, R. Hachmann-Thiessen, and G. Schwarz, J. Polym. Sci., Polym. Chem. Ed., 43, 3667 (2005).

34. H. Ihara, N. Nakamura, S. Nagaoka, and C. Hirayama, Anal. Sci., 111, 739 (1995).

35. R. Yoshida, K. Sakai, T. Okano, and Y. Sakurai, J. Biomater. Sci., Polym. Ed., 6, 585 (1995).

36. Y. Kaneko, S. Nakamura, K. Sakai, A. Kikuchi, T. Aoyagi, Y. Sakurai, and T. Okano, J. Biomater. Sci., Polym. Ed., 10, 1079 (1999).

37. J. Tian, T. A. P. Seery, and R. A. Weiss, Macromolecules, 37, 9994 (2004). 